\title{
ENTREVISTA
}

\section{NOVAS DIRETRIZES PARA EDUCAÇÃO A DISTÂNCIA NO ENSINO BÁSICO}

Dromulgada em fevereiro, Resolução do Ministério da Educação estabelece novas diretrizes para a oferta de educação a distância (EAD) por instituições brasileiras de ensino médio, educação profissional técnica de nível médio e educação de jovens e adultos (EJA) nas etapas do ensino fundamental e do ensino médio. Esta entrevista retoma a evolução histórica das diretivas legais trabalhadas pelo Conselho Nacional de Educação (CNE) e a Câmara de Educação Básica (CEB) para a oferta de e-learning e suas perspectivas para o estudante. 


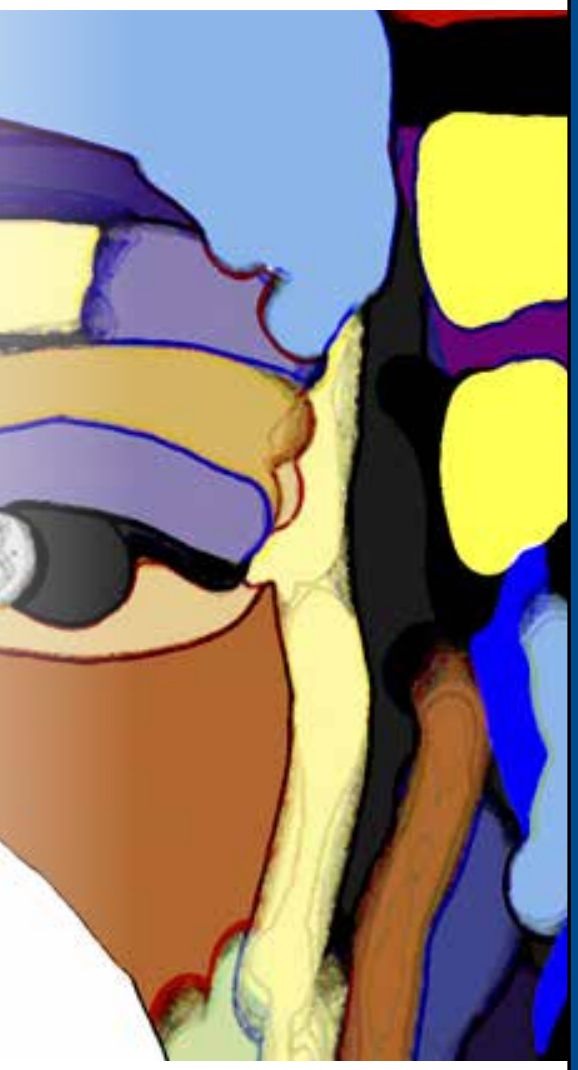

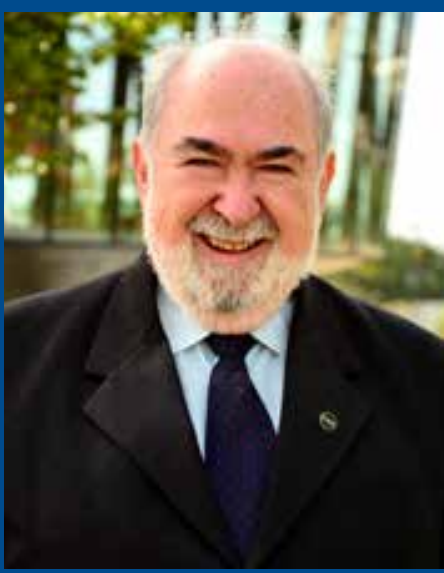

\section{Professor Francisco Aparecido Cordão}

Conselheiro da Câmara de Educação Básica do Conselho Nacional de Educação. Titular da Cadeira n. 28 da Academia Paulista de Educação. Especialista em Educação Profissional e Consultor da Peabiru Educacional.

facordao@uol.com.br

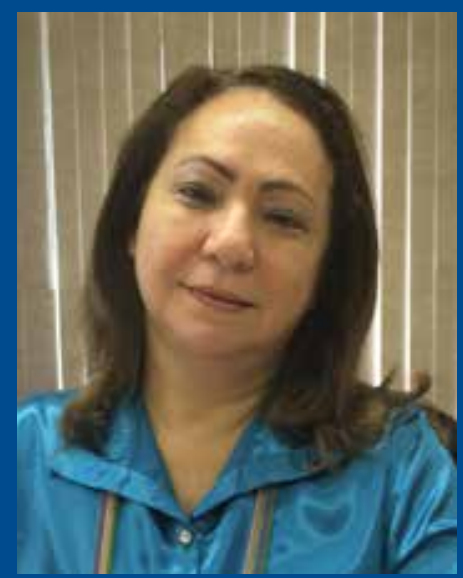

\section{Cassandra} Ribeiro Joye

Coordenadora-geral de Fortalecimento dos Sistemas Públicos de Educação Profissional e Tecnológica na Diretoria de Integração das Redes de Educação Profissional e Tecnológica da Secretaria de Educação Profissional e Tecnológica do Ministério da Educação (Setec/MEC).

cassandra.joye@mec.gov 
Francisco Aparecido Cordão - No ano passado, a Câmara de Educação Básica do Conselho Nacional de Educação aprovou o Parecer CNE/ CEB n. 13/2015, que deu origem à Resolução CNE/CEB n. 01/2016, do ultimo dia 2 de fevereiro, definindo Diretrizes Operacionais Nacionais para o credenciamento institucional e a oferta de cursos e programas de ensino médio, de educação profissional técnica de nível médio e de educação de jovens e adultos, nas etapas do ensino fundamental e do ensino médio, na modalidade EAD, em regime de colaboração entre os sistemas de ensino. O que significa, para o sistema educacional brasileiro, a homologação do Parecer CNE/CEB n. 13/2015 e a decisão da Resolução CNE/CEB n. 01/2016?

Cassandrra Ribeiro Joye - Vejo na Resolução CNE/CEB n. 01/2016 vários significados, sendo dois deles bastante destacados: um de construção coletiva histórica, bottom up, a partir do Fórum Nacional de ConseIhos Estaduais de Educação; e outro, conceitual, do reconhecimento da modalidade EAD para o ensino médio, a educação profissional técnica de nível médio e a EJA, nas etapas do Ensino Fundamental e do Ensino Médio, em regime de colaboração entre os sistemas de ensino da União, dos Estados, do Distrito Federal e dos Municípios.

Para compreender o processo de construção da Resolução, é oportuno resgatar seu histórico. O marco inicial se deu na XVII Reunião Plenária do Fórum Nacional de Conselhos Estaduais de Educação, ainda em 9 de julho de 2002, com a Carta do Maranhão, que colocou em pauta a necessidade de ser definida uma agenda conjunta entre todas as instâncias dos sistemas de ensino, o MEC e o CNE. Essa agenda tinha que referendar a EAD e suas características de exterritorialidade como alternativa de qualidade para o desenvolvimento da educação nacional. Nesse sentido, ainda em dezembro de 2002, foi aprovado o Parecer CNE/CEB n. 41/2002, que instituiu Diretrizes Curriculares Nacionais para a EAD na EJA e para a educação básica na etapa do ensino médio. O Parecer foi devidamente homologado pelo Senhor Ministro da Educação em 23/12/2012, porém, a Resolução decorrente desse Parecer sequer foi publicada, já que o MEC iniciou os debates para a definição do futuro Decreto n. 5.622/2005, de 19/12/2005. Após a edição do referido Decreto, o CNE retomou os debates sobre a matéria. Nesse ínterim, aprovou pareceres casuísticos. Por exemplo, o Parecer CNE/CEB n. 25/2008, que respondeu à consulta sobre os recursos do Fundo de Manutenção e Desenvolvimento da Educação Básica (Fundeb), especificando se eles podem ser aplicados em programas de EAD na EJA, no nível do ensino fundamental e do ensino médio.

Em meados de 2010, a CEB/CNE retomou o debate sobre o regime de colaboração entre os sistemas de ensino para a oferta de EAD, a

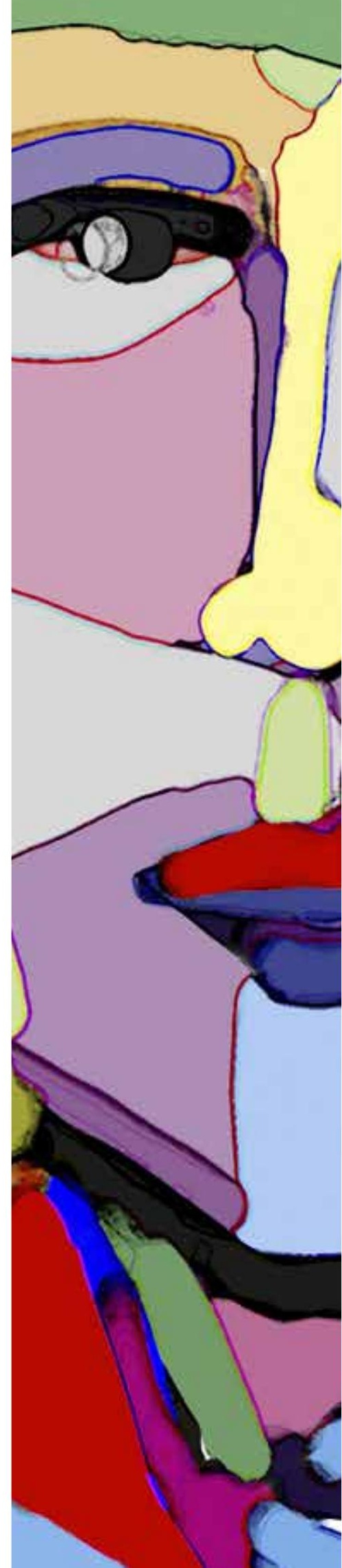


Superior (Sesu), Setec e Diretoria de Educação a Distância da Coordenação de Aperfeiçoamento de Pessoal de Nível Superior (DED/ Capes), cujas recomendações foram encaminhadas, posteriormente, à Consultoria Jurídica da Pasta.

Para a realização da análise técnica solicitada à Setec, foram ouvidas a Diretoria de Políticas da Educação Profissional (DPE) e a Diretoria de Integração de Redes (DIR). Ainda em 2012, foi identificada a necessidade de alguns acréscimos, em termos de fundamentos da organização operacional, notadamente, em relação à educação profissional. Também foram apresentadas algumas ressalvas ao Projeto de Resolução, especialmente considerando a adequação do mesmo à organicidade das instituições de ensino no âmbito dos sistemas federais e estaduais, bem como sua abrangência para a oferta de educação profissional. Realizadas as alterações sugeridas, os documentos normativos em questão foram reencaminhados à análise da Consultoria Jurídica do MEC (Conjur), já no ano de 2013. Ela indicou a necessidade de nova tramitação do processo em questão, para fins de reexame do Parecer CNE/CEB n. 12/2012, com fundamento no $\S 3$ o do Art. 18 do Regimento Interno do CNE. Isso ocorreu, por ofício, em 1/7/2013. A partir daí, gerou-se o Parecer CNE/CEB n. 2/2015, aprovado em 11/03/2015, também de sua relatoria, Conselheiro Francisco Aparecido Cordão, com quem acompanhei exaustivamente esses diálogos.

O referido Parecer CNE/CEB n. 2/2015 foi objeto de nova Nota Técnica elaborada pela Setec, acolhendo as novas recomendações da Conjur, as quais foram acolhidas pelo CNE, em decisão de sua Câmara de Educação Básica, aprovando o Parecer CNE/CEB n. 13/2015. Assim, o novo Parecer do CNE foi devidamente homologado pelo Senhor Ministro da Educação, dando origem à edição da Resolução CNE/CEB n. 1/2016. Essa Resolução, a nosso ver, ainda carece de alguns complementos esclarecedores, mas como se verifica, resulta de um processo de construção de políticas públicas que contou com o mais amplo sentindo de colaboração, para estabelecer significativo regime de colaboração entre os sistemas de ensino no Brasil. Esse é o primeiro significado.

O segundo e mais consequencial significado é o reflexo do objeto para a sociedade: ofertas de cursos e programas de ensino médio e de educação de jovens e adultos na modalidade a distancia, ou seja, em formatos de modelos pedagógicos mediados por tecnologias, que, segundo o estágio atual das mesmas, do conceito de "distante", não há fronteira ou localização geográfica no mundo da virtualidade. 
A EAD, atualmente, usa as tecnologias para eliminar e/ou minimizar as percepções geográficas e territoriais da distância. Daí que o significado de regulamentação do regime de colaboração para a oferta de cursos e programas para esse público-alvo do ensino médio, da educação profissional técnica de nível médio e da educação de jovens e adultos, via mediação de tecnologias na denominada modalidade de EAD, pelo Art. 80 da Lei de Diretrizes e Bases da Educação Nacional (LDB) - Lei n. 9.394/96, definida e regulamentada pelo Decreto n. $5.622 / 2005$ e demais atos normativos, permite ao estudante sair do confinamento de espaço-tempo-deslocamento e encontrar seu curso, realizar seu percurso formativo conforme sua necessidade real de mobilidade, em sua própria localidade ou próximo geograficamente. Esse é o significado conceitual.

Francisco Aparecido Cordão - O Parecer CNE/CEB n. 13/2015, ao elencar as premissas básicas que orientaram a elaboração desses atos normativos, refere-se à obrigatoriedade de dar atendimento ao regime de colaboração entre os diferentes sistemas de ensino, conforme determinado pelo Art. 211 da Constituição Federal e reafirmado pelo Art. $8^{\text {o }}$ da LDB, bem como à necessidade do estabelecimento de regras e normas que orientem claramente a implantação desse regime de colaboração entre os órgãos normativos e de supervisão, para possibilitar a integração dos diferentes sistemas de ensino. A pergunta é: em sua opinião, essas orientações estão suficientemente claras e representam, verdadeiramente, um marco conceitual importante para orientar a oferta de EAD com a devida qualidade?

Cassand ra Ribeiro Joye - Previsto na Constituição e reafirmado pela LDB, o regime de colaboração entre as instituições e sistemas de ensino existe de fato, sobretudo, via programas e projetos e, mais recentemente, via Universidade Aberta do Brasil (UAB) e a Rede Escola Técnica Aberta do Brasil (e-Tec Brasil). A rede federal de ensino, por exemplo, realiza diversas ações de educação profissional e tecnológica em rede. Tal ação é agora fortalecida pela entrada dos Serviços Nacionais de Aprendizagem - Senac; Serviço Nacional de Aprendizagem Industrial (Senai); Serviço Nacional de Aprendizagem do Transporte (Senat); e Serviço Nacional de Aprendizagem Rural (Senar) - no sistema federal de ensino, nos termos do Art. 20 da Lei n. 12.513/2011, na redação dada pela Lei n. 12.816/2013.

Os Conselhos Estaduais de Educação e os órgãos próprios, indicados no âmbito do sistema federal de ensino, terão que estabelecer, se não os têm, os processos de recepção e instalação de polos e de acatamento de cursos de outro estado em sua Unidade - nos termos da Resolução CNE/CEB n. 1/2016, se assim convier ao crescimento da 
região. O que tem de mais rico nesse processo é a força do diálogo e, efetivamente, pensar no sujeito, no cidadão que receberá formação e qualificação técnica via ensino regular a distância. União, Estados, Distrito Federal e Munícipios terão que tomar decisões consensuais para o desenvolvimento regional e nacional. Isso vale para todo ofertante, para que se garanta a qualidade do curso e seu resultado - pessoas formadas e qualificadas, melhoria da condição de empregabilidade, elevação de escolaridade, cidadania plena. Essa nova regulamentação da EAD, em regime de colaboração, com certeza alavancará a educação de qualidade no Brasil, utilizando-se adequadamente das ferramentas e da metodologia/tecnologia da chamada EAD.

Francisco Aparecidlo Cordão - Qual é o entendimento da Resolução CNE/ CEB n. 01/2016 sobre a modalidade EAD e que exigências ela faz para garantir sua oferta com qualidade?

Cassandra Ribeiro Joye - A Resolução CNE/CEB n. 1/2016, como se verifica em sua demanda inicial, explicitada naquela Plenária do Fórum Nacional de Educação lá no Maranhão, no ano de 2002, e culminada nos Pareceres produzidos por CEB/CNE em 2012 e 2015, culminando com a homologação ministerial do Parecer CNE/CEB n. 13/2015, representa, sem dúvida alguma, um marco conceitual importante, na medida em que é um ato normativo que estava fazendo muita falta para promover a grande arrancada da educação a distância com qualidade no Brasil. Sua inexistência dificultava a efetiva colaboração e a nova regulamentação, definida em regime de colaboração entre os diversos sistemas, após muito diálogo entre eles, abre-se à possibilidade de as instituições de ensino compartilharem seus melhores processos e produtos, tais como materiais didáticos, plataformas tecnológicas e resultados de aprendizagem. A principal exigência é deixar clara a organicidade e as competências de cada um quanto à autorização e ao credenciamento para as ofertas em efetivo regime de colaboração. Essa Resolução e seu correspondente Parecer são

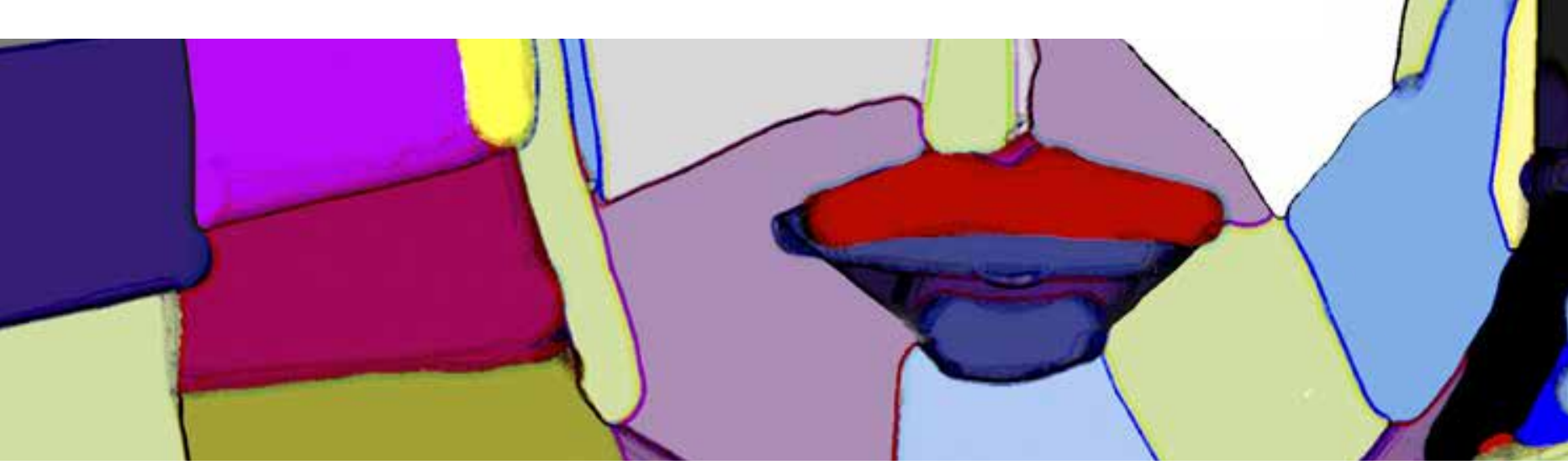




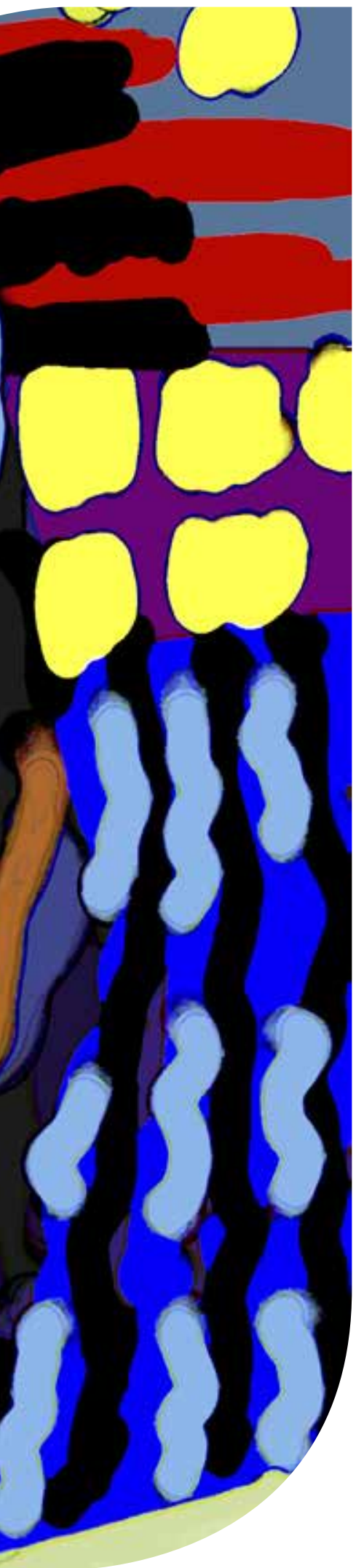

importantes marcos orientadores dos processos legais e normativos de autorização, credenciamento e avaliação.

Por isso mesmo, exige-se que haja uma prévia e rigorosa avaliação por parte dos órgãos próprios de cada sistema de ensino da unidade da federação de origem sobre as condições de viabilidade dos projetos pedagógicos para a implantação da modalidade de ensino a distância com suas peculiaridades, sem perda da qualidade. Para tanto, será necessário cuidar com verdadeiro zelo, entre outros referenciais de qualidade, dos recursos tecnológicos disponibilizados pela instituição de ensino: plataformas, meios e mídias do Ambiente Virtual de Aprendizagem (AVA), transmissão de aulas via satélite, internet, videoaulas, Masssive Open Online Courses (Moocs), telefonia celular, redes sociais, aplicativos mobile learning, TV digital, rádio, impresso e outros que compõem o arsenal de Tecnologias da Informação e Comunicação, todos e cada um usados com suporte de um projeto e modelo pedagógico adequado ao perfil do público-alvo e necessidade da formação dos educandos para a cidadania e o trabaIho, como determina a LDB.

A preocupação maior nesse aspecto tecnológico, aliado ao processo pedagógico, é a de se evitar a precarização do processo de ensino e aprendizagem. A EAD, ao contrário do mito, não é mais com menos; é mais com mais pessoas, recursos tecnológicos, acessibilidade, gestão, controle, qualidade etc. A EAD não é método de ensino com o conceito acentuado, considerando apenas a capilaridade que a modalidade permite, e sim educação mediada por tecnologias, que permite a atuação direta do professor e do aluno em ambientes físicos diferentes, conceitualmente em consonância com o disposto no Art. 80 da Lei n. 9.394/1996 e com o Decreto n. 5.622/2005.

Francisco Aparecido Cordão - Quais as Diretrizes Operacionais Nacionais definidas pela Resolução CNE/CEB n. 01/2016 para as instituições educacionais vinculadas ao sistema federal de ensino?

Cassandra Ribeiro Joye - A Resolução CNE/CEB n. 1/2016, em seus artigos $2^{\circ}, 3^{\circ}$ e $4 \stackrel{\circ}{\circ}$, define o seguinte em relação às instituições educacionais vinculadas ao sistema federal de ensino:

I - Oferta EAD no âmbito estadual próprio:

a) o credenciamento institucional para atuar na modalidade de Educação a Distância, de competência original dos órgãos próprios do MEC, será exercido pelos conselhos superiores dos Institutos Federais de Educação, Ciência e Tecnologia ou similares, 
bem como pelos Conselhos Regionais dos Serviços Nacionais de Aprendizagem, conforme o caso, exercendo função delegada do MEC;

b) no âmbito do sistema federal de ensino, a autorização de funcionamento de cursos na modalidade EAD, em relação à Rede Federal de Educação Profissional e Tecnológica, será concedida, nos termos do Art. $2^{2}$ da Lei n. 11.892/2008, sempre pelos respectivos Conselhos Superiores das Instituições Educacionais da rede federal de ensino e, em relação aos Serviços Nacionais de Aprendizagem, por seus Conselhos Regionais, nos termos do Art. 20 da Lei n. 12.513/2011, na redação dada pela Lei n. 12.816/2013;

c) a supervisão e a avaliação dos cursos serão realizadas em regime de colaboração com os órgãos competentes dos estados e do Distrito Federal, nos termos estabelecidos em atos específicos do MEC;

d) a criação de novos cursos deverá ser comunicada, previamente, pelas referidas IES aos órgãos competentes dos estados e do Distrito Federal, que poderão, a qualquer tempo, pronunciar-se sobre eventual descumprimento dos requisitos necessários para a oferta dos cursos.

II - Oferta EAD fora da unidade da federação de origem, no âmbito do sistema federal de ensino:

1. No caso de Instituições da Rede Federal de Ensino, a abertura dos polos de apoio presencial será autorizada pelo respectivo órgão colegiado superior da instituição de educação profissional vinculada à rede federal de ensino. Conforme essa autorização, para fins de supervisão educacional, deve ser imediatamente comunicada ao MEC, bem como ao correspondente Conselho de Educação dos Estados e do Distrito Federal, para conhecimento e supervisão compartilhada.

2. No caso das instituições educacionais dos Serviços Nacionais de Aprendizagem, para atuação em outras unidades da federação, em estabelecimentos de ensino profissional próprios, a abertura dos polos de apoio presencial será autorizada pelo respectivo 


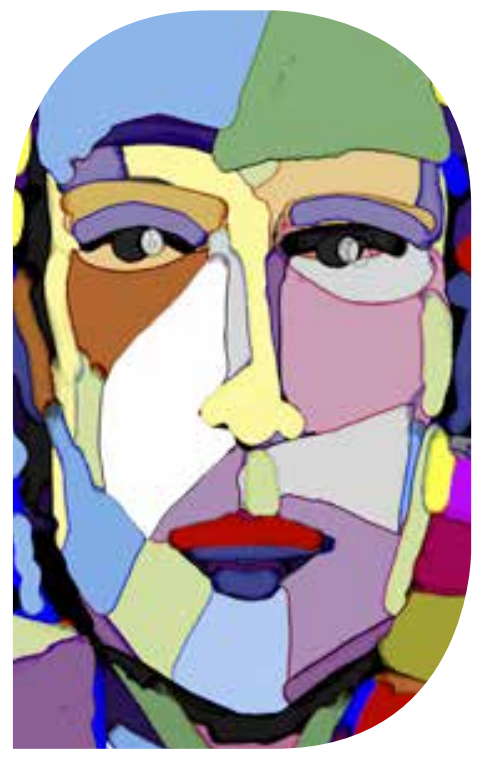

Francisco Aparecido Cordão - Quais as Diretrizes Operacionais Nacionais definidas pela Resolução CNE/CEB n. 01/2016 para as instituições educacionais vinculadas aos sistemas estaduais de ensino?

Cassandra Ribeiro Joye - De acordo com o Art. 40 da Resolução CNE/CEB n. 1/2016, as instituições de ensino públicas vinculadas aos sistemas estaduais de ensino devem se orientar pelas seguintes Diretrizes Operacionais Nacionais:

1. A oferta de ensino médio, de educação profissional técnica de nível médio e de EJA, nas etapas de ensino fundamental e de ensino médio, na modalidade EAD se dará, prioritariamente, no âmbito do próprio sistema estadual de ensino, nos seguintes termos:

a) atenderá ao disposto nas normas definidas pelo respectivo Conselho Estadual de Educação;

b) o credenciamento original da instituição de ensino para atuar na modalidade EAD e a autorização de funcionamento de cursos e programas serão concedidos pelo Conselho Estadual de Educação e terão validade para atuar apenas na sua unidade da federação. 
2. Eventual proposta para oferta de EAD por parte de instituições públicas vinculadas ao sistema estadual de ensino, fora do âmbito estadual de origem, depende de prévia e expressa autorização do correspondente Conselho Estadual de Educação receptor.

Francisco Aparecido Cordão - Você julga que essas normas definidas pela Câmara de Educação Básica do CNE são suficientes para garantir a oferta de cursos e programas de qualidade no âmbito da EAD? O regime de colaboração entre os sistemas de ensino é decisivo para garantir essa qualidade? O que acontece quando a instituição educacional não garantir essa qualidade exigida pelos atos normativos do CNE?

Cassandra Ribeiro Joye - O regime de colaboração instituído e regulamentado é decisivo para a EAD, vez que beneficia as instituições dos diversos sistemas de ensino, que podem, dessa maneira, compartilhar e prover cursos, recursos e materiais didáticos favorecendo diretamente o estudante remoto necessitado de formação e qualificação profissional.

Reforço o entendimento conceitual de EAD, cujo modelo pedagógico (melhor dizendo, andragógico), predominante, é centrado no aprendiz, em geral jovem e adulto e, esse modelo ocorre com a mediação das tecnologias analógicas (ainda, como no caso dos materiais didáticos, impressos e kits didáticos) e digitais. Os modelos pedagógicos decorrentes, por mais lineares e instrucionais que sejam, proveem recursos complementares para que o estudante possua o controle da sua aprendizagem (é ele, estudante, quem escolhe o momento, o lugar, o meio, o ritmo, é a heutagogia).

Dessa forma, quanto mais atrativos e motivadores forem meios, recursos, mídias, materiais e ambientes de aprendizagem, maior qualidade é dada ao sistema ofertante e é apropriada pelo estudante que, aliado a outros recursos, realizará sua formação com qualidade.

A qualidade promove a retenção e diminui a evasão, o que responderia a questão sobre a suficiência da Resolução para garantir a oferta de cursos e programas de qualidade no âmbito da EAD. Ou seja, a Resolução 01/2016 é suficiente do ponto de vista legal, mas não garante a eficácia e qualidade dos modelos pedagógicos. Estes devem ser supervisionados e avaliados com rigor, inclusive nos resultados das formações. 
